\title{
A Bricolage on Perception of Sexuality Education among Medical Students
}

\author{
Lata Ajay Tapnikar* \\ Associate Professor, Department of Community Medicine, NKP Salve Institute of Medical Sciences, Nagpur, Maharashtra, \\ India
}

*Address for Correspondence: Dr. Lata Ajay Tapnikar, 1 Sanjivani, Nelson square, Byramji Town, Chhindwada Road, Nagpur, Maharashtra-440013, India

E-mail: lataajay@rediffmail.com

Received: 07 Dec 2018/ Revised: 17 Mar 2019/ Accepted: 13 Jun 2019

\begin{abstract}
Background: Sexuality education has been one of the highly controversial issues in Indian society. Due to increasing incidences of HIV/AIDS, RTIS/STIs and teenage pregnancies, there is a rising need to impart sexuality education. It is therefore important that young people have adequate information about their sexuality so that they can make informed choices.

Methods: A semi-structured, self-administered questionnaire was used as an instrument for data collection 58 medical students. Convenient sampling method was used to select medical school students in central India. A qualitative study using bricolage and an inductive response was used to construct the article.

Results: There were 75 pre-degree students in faculty of the Medicine. Results and data were statistically analyzed. Only 58 forms could be analyzed. More than $57 \%$ did not know that sex education was taught in schools. Most participants did not know of alternative names for sexuality education. $62 \%$ of the teachers were female. $50 \%$ of the students said that anatomy and contraception were taught to them, while all the students $100 \%$ said that sexuality education is important. $50 \%$ referred to the internet for educating themselves, most participants $67.2 \%$ preferred to discuss among friends. $78 \%$ did not discuss sexuality issues with parents Sexuality education was the need of the hour.

Conclusion: Medical school students were aware of the subject of sexuality education but lack adequate information on sexuality issues. The outcome of our study suggested a need to incorporate it into the school curriculum.
\end{abstract}

Key-words: Bricolage, Inductive response, Medical school students, Perception, Sexuality education

\section{INTRODUCTION}

Sexuality behavior amongst young people is seriously going through a transformation from what it was previously. It is therefore important that young people have adequate information about their sexuality so that they can make informed choices ${ }^{[1]}$. Comprehensive sexuality education received higher ratings than abstinence-only or no sexuality education ${ }^{[2]}$ sexuality education/ family life education (FLE) has been one of the highly controversial issues in Indian society.

Due to increasing incidences of HIV/AIDS, RTIs/STIs, and

\section{How to cite this article}

Tapnikar LA. A Bricolage on Perception of Sexuality Education among Medical Students. SSR Inst. Int. J. Life Sci., 2019; 5(4): 23492354.

\begin{tabular}{|l|c|}
\hline & Access this article online \\
https://iijls.com/
\end{tabular}

teenage pregnancies, there is a rising need to impart sexuality education among youth. Undergraduates of tertiary institutions are predominantly adolescents and young adults, who are at various stages in a continuum of physical and psychological changes associated with enormous social interactions, relationships, and risk behavior ${ }^{[3]}$. However, introducing sexuality education at school level always received a mixed response from various segments of Indian society. More often than not it's their perception towards sexuality and the gaps that are left behind in the present system of teaching sexuality needs to be adequately filled. The problem of over-population also demands family life education, including family planning as a priority, as many of the young people are about to be married and should be aware of the responsibilities they have ${ }^{[2,3]}$. The FLHE program has had positive effects in the states and among schools where the implementation has been effective, 
underscoring the need for more effective implementation of the program throughout the country ${ }^{[4,5]}$. A comprehensive and uniform curriculum on human sexuality at the medical school level may substantially enhance the capacity of tomorrow's physicians to provide optimal care for their patients irrespective of gender, sexual orientation, and individual sexual mores/beliefs ${ }^{[6]}$. To assess the present status by a bricolage, something constructed using whatever comes to hand gives a fairly good idea as to what needs to be recommended. Using these multiple frameworks and methodologies, researchers are empowered to produce more rigorous and praxiological insights into sociopolitical and educational phenomena ${ }^{[7]}$. The inferential thesis with an inductive approach would come near the end of the essay ${ }^{[8]}$. intent being reaching a purposeful course of action thereafter ${ }^{[9]}$. Seymour Papert discussed two styles of solving problems. Contrary to the analytical style of solving problems, he describes bricolage as a way to learn and solve problems by trying, testing, playing around ${ }^{[10,11]}$. An inductive format builds toward a conclusion since an inductive process is "emergent," one thing leading to another, building upon another, like scaffolding, applying a "bricolage" approach" ${ }^{[12,13]}$.

\section{MATERIALS AND METHODS}

A qualitative study was designed using bricolage. This study was conducted using questionnaires distributed to 75 pre-degree students in Faculty of Medicine, MUHS, Nagpur, India between the months of August 2016 to September 2016. A semi-structured, self-administered questionnaire was used as an instrument for data collection. Convenient sampling method was used to select medical school students in the Department of Community Medicine, NKP Salve Institute of Medical sciences and research centre in Nagpur, Maharashtra in central India.

Informed consent was taken from every subject in the form of their signatures. Data collection was done in batches of 8-10 after regular community medicine classes with a pre-tested questionnaire. Each student was made to sit in separate row so that the answers given by them were exclusive to the participant and not through mutual discussion. Before conducting the study, ethical clearance was taken from college ethical committee. Obtained data were statistically analyzed. Only 58 forms could be analyzed as 12 did not return the forms, 2 did not give consent, 3 forms were incomplete.
The inductive responses were obtained in the form of open ended question at the end of the questionnaire.

Statistical Analysis- In this study, P-value $<0.05$ was considered statistically significant. Statistical analysis was analyzed using Epi Info version 7.2.0.1. Categorical variable was expressed as percentages (\%).

\section{RESULTS}

The study group consisted of 58 medical students. Mean age of participants: 21.84, in that batch of medical student participants it was observed that $81.03 \%$ of them were from the age group 20 to 22 years and only $19 \%$ were 23 to 25 years. Female students were more than $60 \%$ as compared to $40 \%$ among male students.

Table 1: Age and Sex wise distribution

\begin{tabular}{cccc}
\hline Age (Yrs) & Female (\%) & Male (\%) & Total (\%) \\
\hline $\mathbf{2 0 - 2 2}$ & $29(50)$ & $18(31.03)$ & $47(81.03)$ \\
$\mathbf{2 3 - 2 5}$ & $6(10.34)$ & $5(8.63)$ & $11(18.97)$ \\
Total & $35(60.34)$ & $23(39.66)$ & $58(100)$ \\
\hline
\end{tabular}

Demographic information- Type of board education and medium of school was analyzed and it was found that 22 (37.93\%) CBSE board, only 2 (3.44\%) ICSE board, 34 (58.62\%), and state board. Total 19 (55.88\%) were from completely English medium schools. All were from Co-ed schools except one from Marathi medium boy's school.

Table 2: Perception of existence of Sexuality education

\begin{tabular}{ccc}
\hline & Yes (\%) & No (\%) \\
\hline SE Taught & $25(43.10)$ & $33(56.90)$ \\
Alternative name of SE & $8(13.79)$ & $50(86.21)$ \\
Attend all sessions & $18(31.30)$ & $40(68.70)$ \\
SE by female teacher & $22(37.93)$ & $36(62.07)$ \\
SE was embarrassing & $4(6.90)$ & $54(93.10)$ \\
SE was Interesting & $24(41.37)$ & $34(58.63)$ \\
Anatomy taught & $29(50.00)$ & $29(50)$ \\
Contraception taught & $28(48.28)$ & $30(51.72)$ \\
\hline
\end{tabular}

More than $57 \%$ did not know that sexuality education was taught in schools. Total $86.2 \%$ did not know of 
alternative names for sexuality education. Total $62 \%$ of the teachers were female. Total $50 \%$ of the students said that anatomy and contraception were taught to them. The interesting part of the study was that $93.1 \%$ did not find sexuality education embarrassing and nearly $58.6 \%$ did not find it interesting.

Table 3: Perception of attitude towards Sexuality Education

\begin{tabular}{|c|c|c|}
\hline & Yes (\%) & No (\%) \\
\hline $\begin{array}{l}\text { SE should be taught in } \\
\text { schools }\end{array}$ & $50(86.21)$ & $8(13.79)$ \\
\hline SE is Important & $58(100)$ & $0(0.00)$ \\
\hline $\begin{array}{l}\text { SE should be part of } \\
\text { Medical curriculum }\end{array}$ & 53(91.38) & $5(8.62)$ \\
\hline $\begin{array}{l}\text { Doubts regarding } \\
\text { sexuality issues }\end{array}$ & $27(46.55)$ & $31(53.45)$ \\
\hline $\begin{array}{c}\text { Doubts to be cleared } \\
\text { by teacher }\end{array}$ & $38(65.52)$ & $20(34.48)$ \\
\hline $\begin{array}{c}\text { Believe in Gender } \\
\text { equality }\end{array}$ & $53(91.38)$ & $5(8.62)$ \\
\hline $\begin{array}{c}\text { Men superior to } \\
\text { women }\end{array}$ & $4(5.90)$ & $54(94.10)$ \\
\hline $\begin{array}{l}\text { Sexuality counseling } \\
\text { need of the hour }\end{array}$ & $46(79.31)$ & $12(20.69)$ \\
\hline
\end{tabular}

It was found that $86.2 \%$ said, sexuality education should be taught in schools. While all the students $100 \%$ said that sexuality education was important. Nearly $50 \%$ of the participants had doubts regarding sexuality issues and $79.3 \%$ felt that Sexuality education was the need of the hour.91.3\% of them believed in gender equality and $94.1 \%$ did not think that men were superior to women.

Table 4: Perception of prevailing practices in Sexuality Education

\begin{tabular}{|c|c|c|c|}
\hline & Yes (\%) & No (\%) & p-value \\
\hline Refer to Internet & $26(44.83)$ & 32 (55.17) & \\
\hline $\begin{array}{l}\text { Discuss among } \\
\text { friends }\end{array}$ & 39 (67.24) & $19(32.76)$ & \\
\hline $\begin{array}{l}\text { Discuss with } \\
\text { Parents }\end{array}$ & $13(22.41)$ & 45 (77.59) & \\
\hline
\end{tabular}

\begin{tabular}{|c|c|c|c|}
\hline $\begin{array}{l}\text { Discuss with } \\
\text { siblings }\end{array}$ & $19(32.76)$ & $39(67.24)$ & \\
\hline $\begin{array}{l}\text { Do your friends } \\
\text { see Adult films }\end{array}$ & $30(51.72)$ & $28(48.28)$ & \\
\hline $\begin{array}{l}\text { Are your friends } \\
\text { sexually active }\end{array}$ & $30(51.72)$ & $28(48.28)$ & $P<0.013$ \\
\hline $\begin{array}{l}\text { Premarital sex is } \\
\text { common } \\
\text { practice }\end{array}$ & $48(82.76)$ & $10(17.24)$ & \\
\hline $\begin{array}{l}\text { Are you in a } \\
\text { relationship }\end{array}$ & 11(18.97) & 47(81.03) & \\
\hline
\end{tabular}

In this study, it found that only $50 \%$ referred to internet for educating themselves, $67.2 \%$ preferred to discuss among friends. Total $78 \%$ did not discuss sexuality issues with parents but $67 \%$ did discuss with siblings. Total $50 \%$ of participants admitted to their friends watching adult films and their friends being sexually active. When gender was assessed then it was found that male watched adult film significantly more than female with $p$ value less than 0.013 . $82.7 \%$ opined that premarital sex is a common practice and when asked if they were in a relationship $81.03 \%$ denied being in it.

Inductive response- Five females and six male students responses have been shared here "Sexuality education should be taught in a way that students, who have not taken up medicine, should not feel embarrassed. Maybe starting in school from an early grade would let young students indulge in acts that they might regret later."

"Sexuality education should be started as early as possible in schools so that difficulties faced by young boys and girls in their adolescence phase can be tackled by them easily and they become more open about issues going on in their minds to people around them, they were free to talk with."

"It should be given to students from school life itself because nowadays due to media students get to indulge in sexual activity very early. Even though, they knew all about contraception and safe period still can commit unwanted mistakes, so it is really necessary. A questionnaire must also include whether they have physically indulged in opposite-sex yet or not? Really this issue must be included compulsorily in all Govt/non-Govt schools."

"Sex education is not a matter of embarrassing moments or any shame in discussing in a group, so this kind of 
stigma should be removed by doing regular sessions on it which can do an ice-breaking for those people and same should be done for gender equality".

"Sex education should be taught to every student as it is very important regarding the health point of view. Since people feel shy talking about this so we need proper knowledge about this" "Teachers shouldn't focus on these things; as students feel very embarrassed".

"Premarital sex should not occur in society coz it has a bad result which can harm society as well as a partner. Equality i.e. Gender should be there in society, no discrimination in society".

"In my school, they have not given education; we have taken the knowledge from the internet. We must take class of sexual educations because many students' boys /girls were shy about sex. Most of the students were shy about talking to girls and boys. Mostly rural area boys were shy for talking"

"Whenever anything we hide from children, they think usually get attracted towards it and they think it's something incredible and the same happening regarding son in developing countries like India. They used to indulge in it in the wrong way. This can be preferred by giving them proper sexual education from childhood."

"Sexuality education is important. Many schools didn't teach it. We have to teach sexual education into the school or to the brother sister. School teachers have to teach properly (khulke)."

\section{DISCUSSION}

A Bricolage qualitative research approach was carried out. Participation was based on informed consent ${ }^{[11,12]}$. We found substantial gap between the proportion of youth, who perceived sexuality education to be important and those who actually received it, revealing considerable unmet need for sexuality education. Mean age of students 21.84 in our study. The mean age of the participants studied by Duru et al. ${ }^{[5]}$ was $22.3 \pm 3.3$ years and in a study by Opora et al. ${ }^{[1]}$, the students were aged 10 - 20 years, with a median age of $15^{[1]}$. Attitudes about reproductive health among males and females aged 1519 years were studied ${ }^{[15]}$. The study found $93 \%$ did not find sexuality education embarrassing. The participants wanted their doubts to be cleared by teachers. Majority of the participants, irrespective of their age and sex, favored introduction of sexuality education at the school level. Increasing the awareness on these topics starting from the school age, young people may understand the right behaviors to adopt for living a healthier life in the interests of themselves and of the entire society ${ }^{[16]}$. Introducing sexual education in schools is generally accepted by respondents of the present study ${ }^{[17]}$. It was found that $86.2 \%$ said that sexuality education should be taught in schools. While all the students $100 \%$ said that sexuality education is important. Around $83 \%$ of young men and $78 \%$ of young women felt that it is important to impart family life/sex education to youth ${ }^{[6]}$. We believe that all types of secondary school should introduce a course of sex education in the curriculum. Science teachers could be responsible for teaching these courses ${ }^{[16]}$. In this study $78 \%$ didn't discuss sexuality issues with parents but $67 \%$ did discuss with friends. Peer education and conventional education strategies were effective in improving the reproductive health knowledge ${ }^{[18]}$. Parentadolescent communication about sexuality has increased during the last few decades; both the occurrence and the quality of this communication could still be greatly improved ${ }^{[19]}$. These results have provided some insight towards the perception of the knowledge attitude and present practices of sexuality among the participants. Sexuality education is the need of the hour. Another study results revealed the feasibility and effectiveness of school based reproductive and sexual health education intervention programs for adolescents ${ }^{[20]}$. In our study $44.83 \%$ referred to internet while another study indicated that for adolescent students the Internet, media, friends, books and magazines were the main sources of information ${ }^{[21]}$. The inductive responses give an honest account of the prevailing situation on sexuality education which often emphasized that sexuality education is need of the hour for adolescents. Increasing the awareness on these topics starting from the school age, young people may understand the right behaviors to adopt for living a healthier life in the interests of themselves and of the entire society ${ }^{[16]}$. Shyness being the major concern it should be taught by properly trained facilitators thus coming to a purposive conclusion and future studies should be designed to center on factors that influence sexual behavior ${ }^{[3,14]}$.

\section{CONCLUSIONS}

A bricolage on perception of sexuality education among medical students was done as a unique qualitative with the inclusion of inductive responses from female and male students, which have been reproduced per se without any modifications. The age mean of students 
was late adolescence. The demographic profile revealed that most students came from English medium schools and their schools did teach sexuality education in the form of anatomy classes taken mostly by a female teacher. $100 \%$ of the students agreed that sex education should be taught in schools. Perception of prevailing practices in sexuality education, internet and adult films seem a common source of information. Students did not discuss sexuality issues with parents or siblings but most often with friends. Male students were significantly more used to seeing adult films as compared to female students. Medical school students were aware of the subject of sexuality education and need adequate information on sexuality issues.

The outcome of our study, we can suggest that the future need to incorporate sexuality education in schools as well as in the medical curriculum.

\section{ACKNOWLEDGMENTS}

The author gratefully acknowledges to the cooperation and support received from the NKP Salve Institute of Medical Sciences, Research center, and Medical students, who were the participants. Dr. Shilpa Hajare, who critically reviewed the article and the Ethical committee members, who allowed me to perform the study successfully.

\section{CONTRIBUTION OF AUTHORS}

The author has singly contributed in this research article.

\section{REFERENCES}

[1] Opara PI, Eke GK, Tabansi PN. Perception of sexuality education amongst secondary school students in Port Harcourt, Nigeria. West Afr. J. Med., 2012; 31(2): 109-13.

[2] Khubchandani J, Clark J, Kumar R. Beyond Controversies: Sexuality Education for Adolescents in India. J. Fam. Med. Prim. Care, 2014; 3(3): 175-79.

[3] Barlow M, Espey E, Leeman L, Scott A, Ogburn T, et al. Satisfaction with Sex Education in New Mexico High Schools: A Survey of College Students. J. Reprod. Med., 2016; 61(3-4): 95-100.

[4] Sallah ED, Grunitzky-Bekele M, Bassabi K, Dodzro K, Sadzo A, et al. Sexual behavior, knowledge and attitudes to AIDS and sexually transmitted diseases of students at the University of Benin (Togo). Sante Montrouge Fr., 1999; 9(2): 101-09.
[5] Duru CB, Iwu AC, Diwe KC, Uwakwe KA, Merenu IA, et al. Sexual Behaviour, Contraceptive Knowledge and Use among Female Undergraduates in Tertiary Institutions in Imo State, Nigeria. Am. J. Med. Sci Med., 2015; 3(5): 61-66.

[6] Tripathi N, Sekher TV. Youth in India ready for sex education? Emerging evidence from national surveys. PloS One, 2013; 8(8): e71584.

[7] Udegbe BI, Fayehun F, Isiugo-Abanihe UC, Nwagwu W, Isiugo-Abanihe I, et al. Evaluation of the Implementation of Family Life and HIV Education Programme in Nigeria. Afr. J. Reprod. Health. 2015; 19(2): 79-93.

[8] Shindel AW, Parish SJ. Sexuality education in North American medical schools: current status and future directions. J. Sex Med., 2013; 10(1): 3-17.

[9] Doubova SV, Infante-Castaneda C, Perez-Cuevas R. Internet-based educational intervention to prevent risky sexual behaviors in Mexican adolescents: study protocol. BMC Public Health, 2016; 16: 343. doi: 10.1186/s12889-016-2990-4.

[10]Bricolage. In: Wikipedia [Internet]. 2018. Available from: https://en.wikipedia.org/w/index.php?title= Bricolag e\&oldid $=850834251$.

[11]Rayner G, Warne T. Interpersonal processes and selfinjury: a qualitative study using Bricolage. J. Psychiatr. Ment. Health Nurs., 2016; 23(1): 54-65.

[12]Gjerberg E, Lillemoen L, Forde R, Pedersen R. End-oflife care communications and shared decisionmaking in Norwegian nursing homes-experiences and perspectives of patients and relatives. BMC Geriatr. 2015; 15: 103. doi: 10.1186/s12877-0150096-y.

[13]Writing@CSU [Internet]. [cited 2019 Jun 6]. Available from: https://writing.colostate.edu.

[14]Varnhagen CK, Svenson LW, Godin AM, Johnson L, Salmon T. Sexually transmitted diseases and condoms: high school students' knowledge, attitudes and behaviours. Can. J. Public Health Rev. Can. Sante. Publique., 1991; 82(2): 129-32.

[15]Mbadu MF, Gahungu NP, Wood F, Bertrand JT. Attitudes toward sexual and reproductive health among adolescents and young people in urban and rural DR Congo. Reprod. Health, 2018; 15(1): 74. doi: 10.1186/s12978-018-0517-4. 
[16]Drago F, Ciccarese G, Zangrillo F, Gasparini G, Cogorno L, et al. A Survey of Current Knowledge on Sexually Transmitted Diseases and Sexual Behaviour in Italian Adolescents. Int. J. Environ. Res. Public Health, 2016; 13(4): 422. doi: 10.3390/ijerph 13040422.

[17]Mutalip SSM, Mohamed R. Sexual education in Malaysia: accepted or rejected? Iran J. Public Health, 2012; 41(7): 34-39.

[18]Parwej S, Kumar R, Walia I, Aggarwal AK. Reproductive health education intervention trial. Indian J. Pediatr., 2005; 72(4): 287-91.
[19]Rufino AC, Madeiro A, Girão MJBC. Sexuality education in Brazilian medical schools. J. Sex Med., 2014; 11(5): 1110-17.

[20]Nair MKC, Paul MK, Leena ML, Thankachi Y, George $B$, et al. Effectiveness of a reproductive sexual health education package among school going adolescents. Indian J. Pediatr., 2012; 79 Suppl 1: S64-68.

[21]McManus A, Dhar L. Study of knowledge, perception and attitude of adolescent girls towards STIs/HIV, safer sex and sex education: (A cross sectional survey of urban adolescent school girls in South Delhi, India). BMC Womens Health. 2008; 23; 8: 12. 